\title{
Gender Representation in Primary Level English and Urdu Textbooks in Pakistan
}

\author{
Rabia Ali \\ Department of Sociology \\ International Islamic University \\ Laila Hussain \\ Women Degree College Skardu \\ Gilgit Baltistan
}

\begin{abstract}
The representation of gender in school textbooks is an area that has been researched in different contexts for decades. It is an area worth investigation because it has been established through research that gender biased textbooks provide hurdles for gender equality in many ways. Taking this as a point of departure this paper aims to examine the representation of male and female in primary level English and Urdu textbooks in Pakistan. To achieve its aim three public and private publishers i.e. AFAQ, National Book Foundation (NBF) and Oxford University Press (OUF) were selected. The text and images in these textbooks were analyzed by using qualitative content analysis. The representation of gender in the selected textbooks was seen through three major themes i.e. visibility of female and male through characters, photographs and narrator of the lesson; activities assigned and vocabulary used for both gender. The data clearly reveals that the visibility of males was much higher than that of females in photographs, images, characters and narrators. Regarding activities assigned to gender in all the selected textbooks women were mostly depicted to be involved in housework and engaged in personal and family activities while boys were shown to be working, playing and engaged in social activities. Finally, it was found that the vocabulary used in the textbooks was stereotypical reflecting existing gender stereotypes in the Pakistani culture. To reduce the gender biased attitude in textbooks it is suggested that a strong gender lens is needed while setting educational policies in the country.
\end{abstract}

Keywords: Gender, Discrimination, Equality, Stereotypes, Visibility, Activities, Textbooks.

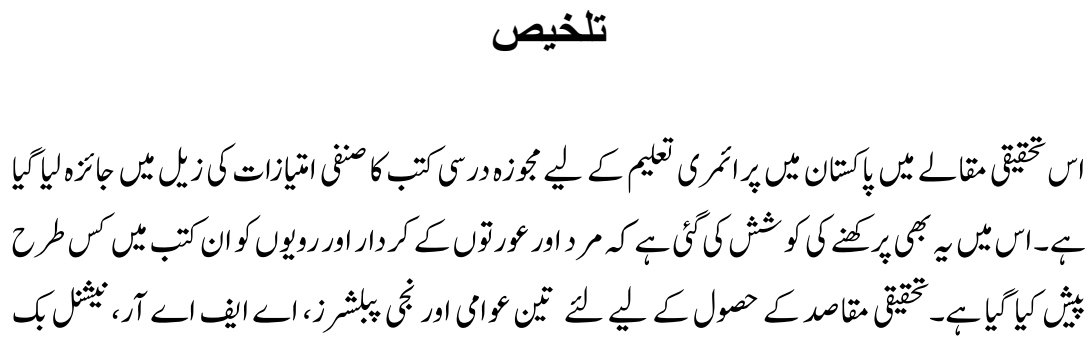




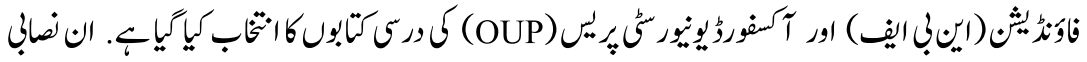

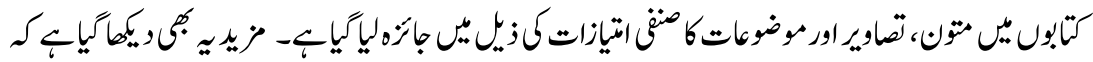

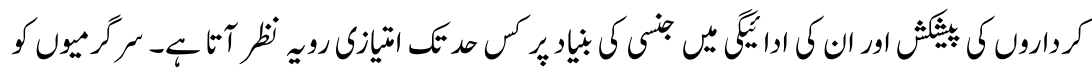

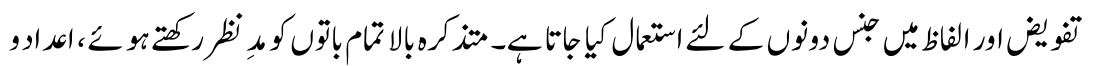

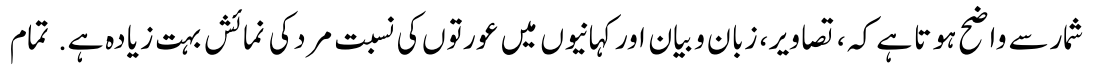

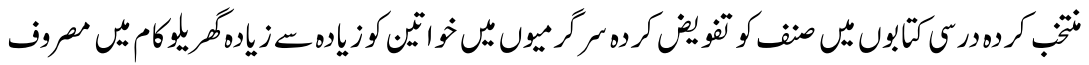

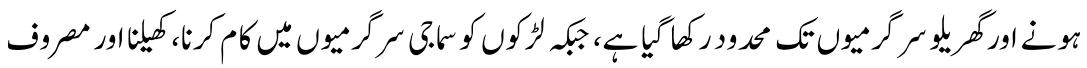

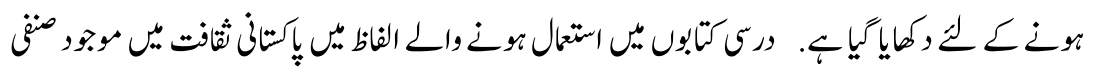

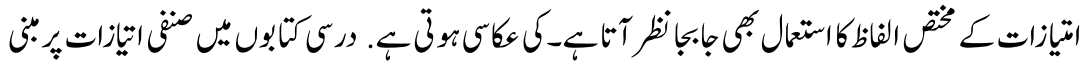

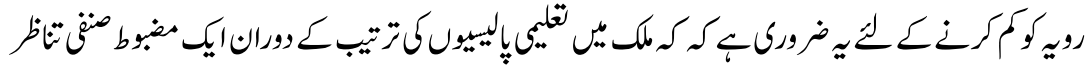

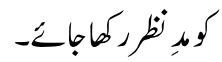

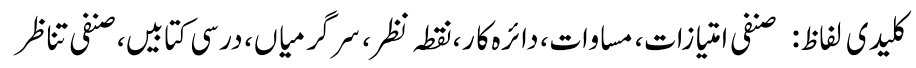

\section{Introduction}

Researches across the world have informed our understanding of how gender is shaped by societal and cultural factors (Pawelczyk, Pakuta, \& Sunderland, 2014; Tahriri \& Pouran, 2014). One of these factors is the representation of gender in textbooks. This has remained an important area of investigation in Sociology and related disciplines and has attracted feminist researchers especially in the field of Sociology of Education for decades (Fox, 1993; Kohl, 1995; Ullah \& Skelton, 1997; Skelton, 2013; Ullah, Ali \& Naz, 2014; Ullah \& Haque, 2016; Visser, 2002). Researchers have reported the prevalence of stereotypical images and text in school textbooks where women have been described in submissive, passive and dependent roles while men have been portrayed as powerful, strong and independent. However, researchers have identified that this illustration of gender roles in school text is problematic since textbooks are argued to have profound influence over young minds (Sulaimani, 2017).

The cognitive and behavioural influence of textbooks on students' learning has been established through various researches (Peterson \& Lach, 1990). Studies in the area of gender and education have highlighted the significance of textbooks in the socialization of children (Lee \& Collins 2009). Further, schoolbooks are considered a vehicle of rules, morals and models of societal behaviour through representations they contain (Oakes \& Saunders, 2004). It has also been argued that school textbooks affect the motivation of students (Ullah \& Skeleton, 2013). 
Importantly, textbooks are believed to have the power of influencing the gender concepts of students. It has been argued that textbooks have the power to influence cultural heritage of learners and the development of gender identity (Ullah, Ali \& Naz, 2014). Gender biased textbooks tend to have adverse affects on the identity, behavior, career aspirations and achievements of individuals especially that of female students (Blumberg, 2009). Thus the knowledge gained through textbooks has regulating power on individuals (Ullah \& Haque, 2016) and textbooks have the power to influence gender stereotypes and social power (Kobia, 2009).

In the context of Pakistan the existing literature has identified that primary school syllabus in the country portray strong gender bias (Ullah \& Skelton, 2013; Ullah $\&$ Haque, 2016). Gender biased text and illustration have been reported in primary school textbooks in Pakistan where the activities of boys and girls have been found to be stereotypical and sexist (Ullah \& Haque, 2016). Likewise, domination of male and representation of women in traditional roles has been raised as a concern in the primary textbooks (Ullah \& Skeleton, 2014). This is so despite Pakistani government's international commitments to ensure gender equality in educational policies and increased emphasis on equality of education in the Pakistani constitution (Government of Pakistan Ministry of Education, 2009; Ullah \& Skelton, 2014; Ullah \& Haque, 2016).

Taking this as a point of departure in this paper we argue that since textbooks are reported to be gender biased these reproduce the existing gender inequalities in the society. Hence, the aim is to identify those patterns in textbooks that reinforce the existing patriarchal structure of the Pakistani society and exhibit gender discrimination through the biased representation of girls and boys. We posit that since textbook are the necessary constituent of education so these have the responsibility to act as vehicle to eliminate gender bias and stereotypes instead of promoting them. This motivates us to investigate gender representation in primary level textbooks in Pakistan particularly focusing on three publishing companies in Pakistan. These include AFAQ, National Book Foundation (NBF) and Oxford University Press (OUP). This was done by examining the visibility of female and male characters, images, tenses and narrator in the selected textbooks.

The publishers AFAQ and NBF are mainly published under the guidance of Ministry of Education while OUP under the supervision of Oxford University Press. However, based on the National curriculum 2006 each book has number of units based on different title and themes. The Oxford University press publishes a range of English and Urdu textbooks at all levels but for English textbooks of OUP we have selected 'Oxford Modern English' and for Urdu 'Meri Kitab'. The main reason for selecting these three publishing companies is the fact that these are widely taught across schools in Pakistan and upon preliminary investigation 
these were found to contain images and text which are to some extent gender biased. Hence, we decided to do further research on these publishers with the aim to highlight the issue of gender representation in the selected books.

The findings of this paper will contribute to the existing body of knowledge on gender representation in textbooks especially from a sociological lens. Though numerous academic studies have been conducted in different contexts and by using different textbooks taught in public and private sector in Pakistan yet studies specifically focusing on the selected textbooks have not been carried out yet. Additionally, we believe that more researches are needed in the Pakistani context on this issue in order to increase our understanding of gender inequalities prevalent in the society and the role of schooling and textbooks in perpetuating such inequalities. Such studies are significant since these will lead to develop strategies and policies for a more gender balanced society in the coming years.

\section{Literature Review}

Gender representation in School textbooks is an area of research that has attracted various disciplines including Sociology of Gender and Sociology of Education for the last few decades and it is an area that is well researched (Clark, \& Mahoney, 2004; Fox, 1993; Kohl, 1995; Oyebola, 2003; Plumm, 2008; Ullah \& Skelton, 2013; Visser, 2002). As a consequence of the extensive studies on children's textbooks, there have been some improvements (Mccabe et. al. 2011). Nevertheless, researches in many countries argue that girls remain under represented in school textbooks especially at primary levels (Skelton, 2011; Ullah $\&$ Skelton 2012). This ultimately influences the status of women across societies. Hence, we believe that the area needs the attention of researchers and policy makers. This is so because textbooks can fix societal problems by redressing the gender inequalities persisting in societies. Hence textbooks are seen as powerful agents of social change as they propagate universal values to pupils (Dejene, 2017). Since pupils' ability to inculcate core values is at its peak during early years of schooling. Therefore, primary level curriculum plays a pivotal role in educating young minds and shaping their personalities. It is largely due to this reason that primary levels of textbooks have attracted the attention of researchers across societies.

Investigation in the field of gender and schooling reveals that school textbooks being a central medium of information in all societies have proved to be a fundamental support for training. Textbooks permit access to all sorts of knowledge. They do not just build up the capability to read and write but they also support crucial judgment, freedom and creativeness. For numerous individuals in the private world who do not have access to reading material for whatever reasons there may be, textbooks offer an introduction to the print media. Importantly, 
textbooks are important in gender socialization of children (Lee \& Collins 2009). Textbooks put forward variety of identities, comforts, attitudes, and experiences for children. Basic level textbooks are measured as mostly significant, as they include the necessary realistic facts and skills that kids are thought to attain, which robustly influence their outlook of life, their gender socialization, and the imitation of gender inequality and stereotypes in the culture (Thun, 2001). Textbooks are deployed in transmitting not only some knowledge regarding a specific subject but they also have a significant role in conveying the view point of the textbook producers (Mineshima, 2008).

As far as the sex illustration in textbooks is concerned gender discrimination and biasness has been reported in many studies. Stockdale (2006) for example evaluated the series concerning sex unfairness linked matters that involve reflectivity, firstness, nouns, pronouns and discourse characters. His investigation revealed that the series showed a meaningful partiality in favour of men. Likewise, high school chemistry textbooks were examined by Bazler \& Simonis (1991). They investigated that there was an imbalance somehow in sex depiction. The chemistry tutors were stimulated by the writers to examine the textbooks cautiously for the promotion of sex equivalence.

The literature regarding sex roles in textbooks described in various studies have predominantly focused on two important aspects including visibility and attribution. It has been reported that irrespective of the roots of textbooks, men are more observable in texts and graphics than women. A study conducted by Neutze (2008) illustrated the unequal ration of male and female in textbooks. It was reported to be 1.5:1 in whole design and 2:1 as leading roles. History books were studied by Lerner and Nagai (1991) for contrary dealing by sex. They investigated that males were stated seven times more frequently than females in the textbooks of History, but females were stated in a constructive way.

Likewise, Gisnet (1988) in the context of Israel reported 89\% male in English textbooks. As a whole, the percentage of females was 33 of all the roles. Hellinger (1980) highlighted that women were omitted from the names of stories, and women occurred in less than 10 percent of the story names in English linguistic textbooks used in German institutes. In the mainland Chinese linguistics textbooks out of 93 roles 82 were found to be male (Ning, 1992). Blumberg (2009) studied textbooks from in different contexts across the world and found that sex labels and women under-representation are still widespread. In a study on usage of online syntax guide by students Amare (2007) found that in illustration of linquistic make references were used three times more than female ones. Likewise, Turner-Bowker (1996) studied that women in kids fiction were usually accorded weakness, submissiveness, negative appraisal, and femaleness, whereas, the men attributes contain power, action, positive appraisal and maleness. Women 
were mostly portrayed as good-looking, precious, sweet, feeble and afraid, whereas males were immense, horrifying, brutal, great, awful, enraged, daring and superior.

An analysis of twenty four school textbooks by Ullah and Haque (2016) taught in public schools in Pakistan found gender biased text and illustrations. The activities of boys and girls were found to be stereotypical. Gender bias was also found in dialogues and conversations. Male were shown in central characters. Trips and excursions too were found to be gendered. Based on their findings the authors argue that the representation of gender in textbooks children understands of appropriate behavior in the society (Ullah \& Haque, 2016). Likewise, a similar study in Pakistan reports dominance of male in school textbooks. The study reports that female are depicted in traditional gender roles and hence the textbooks reinforce the patriarchal family structure (Ullah \& Skeleton, 2014).

However, in contrast to the above researches discussed here, some studies have revealed that males and females are depicted similarly, for instance, by using a critical discourse investigation technique Tahriri and Pauran (2014) worked on the Top Notch Sequence in terms of sex depiction. They did the investigation of three main features of sex, namely associations, locations, and content centred on the three dimensional model of Fairclough (2001). They examined that males and females were characterized in a same manner. Their investigation revealed that the sequence has resorted to the entrepreneurship thought in representing sex.

The above studies inform us about the visibility of women and men in text in different contexts. Clearly discriminatory and unequal portrayal of men and women is widespread in textbooks across the world. These studies clearly highlight that how boys and girls are represented in school textbooks is problematic. School textbooks educate the young minds to behave in certain way. This in fact leads to the internalization of the patriarchal mindset by the young boys and girls who inculcate gender biased attributes through the textbook which they later reinforce in their adulthood. Hence, the cycle of male domination and power continues. Hence, this warrants the need to study textbooks from a critical lens since this is an area that needs attention especially from those doing researches within Sociology of Education. This is important since understanding the how women and men are represented in textbooks may guide us to provide relevant recommendations at policy level to reduce gender bias in curriculum for a more gender balanced society.

\section{Methodology}

This paper takes a liberal feminist lens to study gender representation in textbooks (Alvesson \& Skoldberg, 2017; Anderson, 2002). A qualitative content analysis 
has been used to analyze gender representation in the selected textbooks. Qualitative content analysis is one of the many methods that have been utilized to examine the text data. The researchers who have used this method mainly focus on the language as communication by highlighting the content and contextual meaning of text and images (Tesch, 1990). This paper is inspired by the qualitative content analysis as proposed by Hsieh and Shannon (2005). They have proposed three types of qualitative content analysis i.e. conventional, directed and summative. These tend to conceptualize textual data in realistic perspective.

Conventional content analysis is specifically utilized in the study whose purpose is to define the particular phenomena and it is usually suitable when the prevailing theory and literature is limited on that phenomena. Predetermined classifications are avoided (Kondracki \& Wellman, 2002) instead it allows codes to flow from data. It is an inductive approach which involves immersion in data. Its goal is to authorize or prolong a theory (Mayring, 2000). Directed content analysis is more organized procedure in which the codes emerge from existing theory or literature (Hickey \& Kipping, 1996). The purpose is theory validation.

Finally, in summative approach, definite words or contents in the text are counted with the aim to understand their textual use. The purpose of this quantification is not to infer meaning as such but to explore the usage practice and norm (Potter \& Levine-Donnerstein, 1999; Hsieh \& Shannon, 2005). In the final stage of this approach the focus is on understanding the underlying meaning of the word and the content (Babbie, 1992). In this paper summative approach has been used to interpret the data.

\section{The Material for the Research}

The major concern of this research is to highpoint the representation of gender in primary level Urdu and English textbooks of three public and private publishers including AFAQ, NBF and OUF. The textbooks which were selected are taught both in public and private schools in Pakistan. For the selection of textbooks purposive sampling technique was used. Prior to the selection of textbooks ten private schools were visited in Islamabad and the selection of textbooks was made in the light of their frequency of being used in schools.

\section{Key Findings from the Selected Textbooks}

1. Male characters were more visible in all the selected textbooks compared to female characters.

2. The activities assigned to gender reflected the stereotypical roles assigned to men and women in the Pakistani society. 
3. The vocabulary used to represent female and male in the selected textbooks present and reinforce the stereotypical language used in the Pakistani culture.

\section{Findings and Discussion}

\section{Visibility}

Visibility of female and male is a major manifestation of sexism in schoolbooks, which is also called omission, where the appearance of female is often less than men. It speaks of the undermining of female as compared to male in text (Porreca 1984, p. 706). Visibility in the selected textbooks was determined through visibility through characters, visibility through photographs and narrator of the lesson. These have been presented in the table 1.1 and will be discussed below.

Table: 1.1

Visibility through female and male characters

\begin{tabular}{|c|c|c|c|c|c|c|}
\hline \multirow{3}{*}{$\begin{array}{l}\text { Visibility } \\
\text { of Gender } \\
\text { Character }\end{array}$} & \multicolumn{6}{|c|}{ English Books } \\
\hline & \multicolumn{3}{|c|}{ Male } & \multicolumn{3}{|c|}{ Female } \\
\hline & AFAQ & NBF & OUP & AFAQ & NBF & OUP \\
\hline $\begin{array}{l}\text { Main } \\
\text { Characters }\end{array}$ & $\begin{array}{c}88 \\
(66.2)\end{array}$ & $\begin{array}{c}24 \\
(61.5)\end{array}$ & $\begin{array}{c}37 \\
(73)\end{array}$ & $\begin{array}{c}45 \\
(33.8)\end{array}$ & $\begin{array}{c}15 \\
(38.5)\end{array}$ & $\begin{array}{c}14 \\
(27.5)\end{array}$ \\
\hline $\begin{array}{l}\text { Supporting } \\
\text { Characters }\end{array}$ & $\begin{array}{c}39 \\
(45.9)\end{array}$ & $\begin{array}{c}26 \\
(76.5)\end{array}$ & $\begin{array}{c}24 \\
(63.5)\end{array}$ & $\begin{array}{c}46 \\
(54.1)\end{array}$ & $\begin{array}{c}8 \\
(23.5)\end{array}$ & $\begin{array}{c}14 \\
(37)\end{array}$ \\
\hline Total & $\begin{array}{c}127 \\
(58.3) \\
\end{array}$ & $\begin{array}{c}50 \\
(68.5) \\
\end{array}$ & $\begin{array}{c}61 \\
(68.5) \\
\end{array}$ & $\begin{array}{c}91 \\
(41.7) \\
\end{array}$ & $\begin{array}{c}23 \\
(31.5)\end{array}$ & $\begin{array}{c}28 \\
(31.5) \\
\end{array}$ \\
\hline \multirow{3}{*}{$\begin{array}{l}\text { Visibility } \\
\text { of Gender } \\
\text { Character }\end{array}$} & \multicolumn{6}{|c|}{ Urdu Books } \\
\hline & \multicolumn{3}{|c|}{ Male } & \multicolumn{3}{|c|}{ Female } \\
\hline & AFAQ & NBF & OUP & AFAQ & NBF & OUP \\
\hline $\begin{array}{l}\text { Main } \\
\text { Characters }\end{array}$ & $\begin{array}{c}106 \\
(65.4)\end{array}$ & $\begin{array}{c}39 \\
(69.6)\end{array}$ & $\begin{array}{c}56 \\
(81.2)\end{array}$ & $\begin{array}{c}56 \\
(34.6)\end{array}$ & $\begin{array}{c}17 \\
(30)\end{array}$ & $\begin{array}{c}13 \\
(18.8)\end{array}$ \\
\hline $\begin{array}{l}\text { Supporting } \\
\text { Characters }\end{array}$ & $\begin{array}{c}140 \\
(79.1)\end{array}$ & $\begin{array}{c}141 \\
(87.5)\end{array}$ & $\begin{array}{c}33 \\
(86.5)\end{array}$ & $\begin{array}{c}37 \\
(21)\end{array}$ & $\begin{array}{c}20 \\
(12)\end{array}$ & $\begin{array}{c}5 \\
(13.5)\end{array}$ \\
\hline Total & $\begin{array}{c}246 \\
(72.6)\end{array}$ & $\begin{array}{c}180 \\
(82.9)\end{array}$ & $\begin{array}{c}89 \\
(83.2)\end{array}$ & $\begin{array}{c}93 \\
(27.4)\end{array}$ & $\begin{array}{c}37 \\
(17)\end{array}$ & $\begin{array}{c}18 \\
(16.8)\end{array}$ \\
\hline
\end{tabular}

The above table shows the result of visibility through characters in the English and Urdu textbooks of AFAQ, NBF and OUP. The table clearly depicts that in English textbooks the total percentage of female characters including main and supporting characters was 41.7 in AFAQ, 31.5 in NBF and 31.5 in OUP and that of male was found to be $58.3 \%$ in AFAQ, 68.5 in NBF and 68.5 in OUP. When it comes to Urdu textbooks, the percentage of main and supporting male characters 
was 72.6 in AFAQ, 82.9 in NBF and 83.2 in OUP in contrast to 27.4 female in AFAQ, 17 in NBF and 16.8 in OUP.

This clearly illustrates that the main and supporting characters were assigned to male in all three selected textbooks. This was true in both English and Urdu textbooks. The gender bias for supporting character was very vivid in case of NBF where 20(12\%) female in contrast to $141(87.5 \%)$ male was found.

Hence, analysis of the three textbooks in terms of characters highlights that male characters outnumbered females in the selected textbooks. There were clearly more characters in the AFAQ sun series than NBF and OUP. On this basis it can be anticipated that the discourses related to gender are also more profuse and diverse in AFAQ. On the other hand in NBF the female representation through main and as well as supporting characters were very less compare to rest of the textbooks. Likewise, when the comparison was made related to visibility in photographs gender imbalance in three of the English and Urdu textbooks was present. Male representation in pictures was much higher than female in all three textbooks. This ratio was higher in NBF and OUF compared to AFAQ. This gender imbalance reflects the patriarchal mind set of the Pakistani Society. In addition, it also raises serious concerns about the authorship of these textbooks and the policies of the publishers. Clearly, there is need to have more gender neutral and gender sensitive policies to remedy this issue.

The above findings are similar to other studies reported by feminist writers in other parts of the worlds and in Pakistan too. Previously it has been reported that male characters in textbooks out number females. For example the study of Sajjadi (2004) reports that the male and female ratio in English as foreign language textbook was 6:1. More pictures and biographies of male were found in these text compared to female. Likewise, according to Ullah and Skelton (2013) the word he/him occurred more than she/her. In this study the authors have reported that male were portrayed in leading roles and made up $73 \%$ of those represented in 30 biographies.

Table: 1.2

Gender visibility in photographs of english textbooks

\begin{tabular}{|c|c|c|l|l|l|l|}
\hline \multirow{2}{*}{ Book } & \multicolumn{3}{|c|}{ Female } & \multicolumn{3}{c|}{ Male } \\
\cline { 2 - 7 } & AFAQ & NBF & OUP & AFAQ & NBF & OUP \\
\hline English & 179 & 179 & $216(34.3)$ & $350(66.2)$ & $245(58.7)$ & $414(65.7)$ \\
& $(33.8)$ & $(42.2)$ & & & & \\
\hline Urdu & $179(35.9)$ & $34(23.9)$ & $70(19.6)$ & $320(64.1)$ & $108(76)$ & $287(80.4)$ \\
\hline
\end{tabular}

Likewise, the gender imbalance was clearly evident through the analysis of photographs. Male's visibility was found to be higher compared to female in all the selected images from the textbooks. In numerous cases, images of the same men were repeated quite a number of times in different places in the textbook and in some cases there were multiple images on the same page. In AFAQ textbooks 
the number of males appearing in the given images in English textbooks were $66.2 \%$ and that of female were $33.8 \%$. In case of Urdu textbooks $35.9 \%$ female and 64.1 male images were present. In NBF the total no of appearances of both gender in the English book was 424. Out of this men were 245(58.7\%) in pictures in contrast to $179(42.2 \%)$ women. In Urdu books the illustrations of male and female were $76 \%$ and $23.4 \%$ respectively. In case of OUP textbooks in English textbook, out of 630 images, there were only 216(34.3) female whereas 414(65.7) male. Similarly, in Urdu books, from the total of 357 images $70(19.6 \%)$ were the images of female whereas $287(80.7 \%$ ) were images of male. This again illustrates a strong gender imbalance in the selected textbooks.

Comparing these findings with the related studies conducted previously in this area it seems that similar findings were reported earlier too. In a study on the gender balance in illustration of textbooks carried out by Oyebola (2003) it was found that the selected textbooks included gender imbalanced illustrations. The findings of the present study are also similar to the findings from the study done by Ismail et al, (2012). However, the findings obtained from above table oppose Dominguez (2003) who has argued that the trend is changing and publishers are careful not to publish gender sensitive contents in school textbooks.

Table: 1.3

Narrator of the lesson in english textbooks

\begin{tabular}{|l|l|c|c|c|c|c|c|}
\hline \multicolumn{2}{|l|}{$\begin{array}{l}\text { Narrator of the } \\
\text { Lesson in English } \\
\text { textbooks }\end{array}$} & \multicolumn{3}{|c|}{ Male } & \multicolumn{3}{c|}{ Female } \\
\cline { 3 - 8 } & AFAQ & NBF & OUP & AFAQ & NBF & OUP \\
\hline \multirow{3}{*}{ Book } & English & 25 & 13 & 20 & 12 & 8 & 15 \\
\cline { 2 - 8 } & Urdu & 36 & 21 & 45 & 15 & 16 & 23 \\
\hline
\end{tabular}

The above table shows that the frequency of repetition of male narrators was more compared to females in all the selected textbooks. In case of AFAQ English textbooks, out of 67 stories only 12 were narrated by females, 25 by males and in 30 stories gender was not specific. Similarly in AFAQ Urdu textbooks there were total 122 stories in which 15 were narrated by females, 36 by males and in remaining 71, gender was not distinguished. In NBF English textbooks there were 13 men, 8 women, and in the rest of the 21 lessons, the gender of the narrator was not specific. On the other hand, in Urdu book out of 67 stories there were 21 men, 16 women and 30 without specific gender. Finally in OUP from total 60 chapters in English books of class 1 to 5 only 20 were narrated by males, 15 by female and in 25 chapters the narrator was not specific. While in Urdu textbooks only 23 were females and the remaining 45 were males. This analysis also shows discrimination in the way women and men are portrayed in the selected textbooks.

\section{Activities Assigned to Both Gender}

Representation of boys and girls in activities has been an area researched previously. Different researches have shown that men are generally involved in 
activities like gardening, fixing, repairing, playing, and educational activities whereas on the other hand women are involved in activities like dishwashing, laundry, childcare, and cooking. In a study of school textbooks in the KPK Province of Pakistan Ullah \& Haque (2016) found that boys were involved in activities including, exercising, flying kites, helping others outside home, discussing reform of society, posting letters, helping fathers in harvesting. In the same study girls on the other hand were depicted within the domestic domain engaged in activities like reciting Quran, serving grandmother, disposing garbage, praying, serving food and cooking etc. Hence, considering the importance of activities assigned to genders in previous studies the same was analyzed in this research as well. The results are presented in table 2 below.

Table: 2

Activities assigned to gender

\begin{tabular}{|l|c|c|c|c|c|c|c|c|c|c|c|c|}
\hline \multirow{3}{*}{ Male and female Activities } & \multicolumn{4}{|c|}{ English } & \multicolumn{5}{c|}{ Urdu } \\
\cline { 2 - 14 } & AFAQ & \multicolumn{2}{|c|}{ NBF } & \multicolumn{2}{|c|}{ OUP } & AFAQ & NBF & \multicolumn{1}{|c|}{ OUP } \\
\cline { 2 - 13 } & F & $\mathbf{M}$ & $\mathbf{F}$ & $\mathbf{M}$ & $\mathbf{F}$ & $\mathbf{M}$ & $\mathbf{F}$ & $\mathbf{M}$ & $\mathbf{F}$ & $\mathbf{M}$ & $\mathbf{F}$ & $\mathbf{M}$ \\
\hline Doing housework & 3 & 0 & 4 & 0 & 4 & 0 & 0 & 0 & 0 & 0 & 8 & 0 \\
\hline Working & 0 & 10 & 7 & 11 & 11 & 9 & 0 & 6 & 2 & 5 & 9 & 5 \\
\hline Studying & 3 & 36 & 12 & 18 & 1 & 19 & 0 & 4 & 2 & 9 & 3 & 27 \\
\hline Playing & 12 & 21 & 0 & 1 & 11 & 24 & 7 & 8 & 0 & 0 & 6 & 26 \\
\hline Relaxing/Resting & 4 & 11 & 9 & 9 & 6 & 8 & 8 & 8 & 4 & 3 & 8 & 5 \\
\hline Engaged in Social activities & 9 & 11 & 11 & 16 & 2 & 4 & 0 & 14 & 2 & 3 & 2 & 13 \\
\hline $\begin{array}{l}\text { Engaged in Personal/ } \\
\text { family activities }\end{array}$ & 8 & 5 & 4 & 0 & 8 & 9 & 5 & 9 & 0 & 0 & 5 & 5 \\
\hline
\end{tabular}

The above table shows that similar to the findings of previous studies discussed above in the selected textbooks too all the selected textbooks women were mostly depicted to be involved in housework and engaged in personal and family activities while boys were portrayed to be working, playing and engaged in social activities. Hence, through these gendered messages the young men and women are informed about their feminine and masculine images and conducts (Skeggs, 2002).

\section{Vocabulary Used}

The existing literature on gender representation in textbooks shows that gender biased vocabulary is common in textbooks. For example Dixon (2005) has found that words like angry, happy, sad, clever, and honest supportive, friendly, kindhearted and sociable are often used to differentiate male and female characters in textbooks.

Vocabulary used in the selected textbooks was also critically examined in this study. While doing the analysis more focus has been given to the adjectives, which were used to describe the characteristics of both gender. In the Pakistani 
society, there are some words which are specifically used for female like beautiful, emotional and pretty, whereas on the other hand words often associated with men include handsome, brave and rational. In the light of this common stereotypical division of words the researcher attempted to analyze if the same patterns were present in the selected textbooks.

Table: 3

Adjective used for gender

\begin{tabular}{|c|c|c|}
\hline Books & English book & Urdu book \\
\hline \multicolumn{3}{|c|}{ Adjectives for Female } \\
\hline AFAQ & $\begin{array}{l}\text { Caring, beautiful, simple, } \\
\text { hardworking, good cook, clever, } \\
\text { kind hearted, respectful, creative, } \\
\text { good server, weak, happy. }\end{array}$ & $\begin{array}{l}\text { Khoubsurat, piyari, lalachi, } \\
\text { zaheen, samjdar, salleeqa mand, } \\
\text { chalak, Hoshiyar, masoom* }\end{array}$ \\
\hline $\mathrm{NBF}$ & $\begin{array}{l}\text { Intelligent, tall, dirty, emotional, } \\
\text { beautiful, care taker, greedy, thin, } \\
\text { kind hearted, intelligent, smart. }\end{array}$ & $\begin{array}{l}\text { lalachi, zaheen, samjdar, , } \\
\text { salleeqa mand, chalak, Hoshiyar, } \\
\text { masoom* }\end{array}$ \\
\hline OUP & $\begin{array}{l}\text { Faithful, confused, devoted, clean, } \\
\text { beautiful, cleaver, pretty, naughty } \\
\text { Hard work, Honest, fat, care taker, } \\
\text { disciplined, loyal, lovely, } \\
\text { charming. }\end{array}$ & $\begin{array}{l}\text { lalachi, Naik, ebadaatguzar, } \\
\text { zaheen, samjdar, Chitkhori, } \\
\text { salleeqa mand, chalak, Hoshiyar, } \\
\text { masoom* }\end{array}$ \\
\hline \multicolumn{3}{|c|}{ Adjectives for Male } \\
\hline AFAQ & $\begin{array}{l}\text { Lazy, intelligent, cleaver, healthy, } \\
\text { Intellectual, slow, obedient, } \\
\text { active, intellectual, punctual, } \\
\text { loving, careless, naughty, } \\
\text { respected, wise respectful. }\end{array}$ & $\begin{array}{l}\text { rehamdil, tameez dar, chota, } \\
\text { tang, bechary, acha, kamzor, } \\
\text { sharer, khush haal, tandurast, } \\
\text { nojaawan, taqatwaar, mascara, } \\
\text { aqil mand* }\end{array}$ \\
\hline NBF & $\begin{array}{l}\text { Hardworking, wise, handsome, } \\
\text { naughty, cleaver, rational, } \\
\text { courageous, brave, bread winner, } \\
\text { strong, intelligent, careless }\end{array}$ & $\begin{array}{l}\text { rehamdil, tameez dar, chota, } \\
\text { tang, bechary, acha, kamzor, } \\
\text { sharer, khush haal, tandurast, } \\
\text { nojaawan, taqatwaar, mascara, } \\
\text { aqil mand* }\end{array}$ \\
\hline OUP & $\begin{array}{l}\text { Hardworking, wise, handsome, } \\
\text { naughty, clever, creative, tall, } \\
\text { rational, Strict, Rude, courageous, } \\
\text { brave, honour saver, bread } \\
\text { winner, strong, intelligent, lazy, } \\
\text { careless }\end{array}$ & $\begin{array}{l}\text { Naik, rehamdil, piyara, tameez } \\
\text { dar, golmotol, narm, chota, tang, } \\
\text { bechary, acha, kamzor, sharer, } \\
\text { khush haal, tandurast, borhy, } \\
\text { nojaawan, mahir, taqatwaar, } \\
\text { mascara, aqil mand* }\end{array}$ \\
\hline
\end{tabular}

*These Urdu words have been translated below.

The data in this study illustrates that adjectives used to represent female and male in the selected textbooks present and reinforce the stereotypical language used in our 
culture. For example in the Pakistani society boys are generally depicted as lazy, intelligent, careless, wise and healthy while on the other hand and women are depicted as caring, respectful, loving and kind hearted. Comparison on the basis of vocabulary shows that the adjective which were used for both gender in all of the three textbooks were similar and portrayed the stereotypical images of women and men existing in our society. Majority of the adjectives used for females referred to the personality and physical appearance of females such as beautiful, slim, young, emotional, attractive, shy, sincere, fat, curing and so on. On the other hand adjectives used for male characters, were related to personality of men such as courageous, brave, obedient, active, educated, proud, rude, and so on.

In AFAQ series the adjectives used for female in English books were beautiful, simple, hardworking, good cook, clever, kind hearted, respectful, creative, good server, weak, and happy. The adjectives used for male in AFAQ series included lazy, intelligent, cleaver, healthy, Intellectual, slow, obedient, active, intellectual, punctual, loving, careless, naughty, respected, wise and respectful. In NBF English textbooks the adjective used for women intelligent, tall, dirty, emotional, beautiful, care taker, greedy and thin. While for men the adjectives used included hardworking, wise, handsome, naughty, cleaver, rational, courageous, brave, bread winner, strong, intelligent and careless. In OUP English textbooks the adjectives used for females included words like faithful, confused, devoted, clean beautiful, cleaver, pretty, naughty, hard work, Honest, fat, care taker, disciplined, loyal, lovely, charming. On the other hand for men the adjectives used included hardworking, wise, handsome, naughty, clever, creative, tall, rational, strict, rude, courageous, brave, honour saver, bread winner, strong, intelligent, lazy and careless.

The adjectives used for both male and female in the Urdu textbooks also portrayed similar patterns. In the AFAQ, NBF and AUP Urdu textbooks adjectives attributed to female included Khoubsurat,(beautiful), samjdar,(sensible) salleeqa mand (well mannered), lalachi (greedy) and masoom (innocent). The adjectives used for male in the three textbooks included rehamdil (kind hearted), tameez dar (well mannered), bechary (poor), acha (good), sharer(naughty), khush haal (well off), tandurast (healthy), nojaawan (young), taqatwaar (strong), aqil mand (intelligent). These adjectives clearly depict the stereotypes assigned to both gender in the Pakistani society.

\section{Conclusions}

Considering the significance of empirical researches on gender equality in all life domains, this research was conducted to examine the representation of gender in three different textbooks which are taught in different schools of Pakistan at governmental and private levels. The primary question that guided this study was how boys and girls are portrayed in the selected primary Urdu and English textbooks. The analysis evidences gender bias in textbooks despite the commitment of the Pakistani state to gender equality at all levels. 
The findings have clearly highlighted that females are excluded in several ways. The main characters are often assigned to boys; the major themes in textbook portray boys/men; important roles in text are assigned to boys/men and finally major responsibilities are attached to boys/men. Girls were highlighted to be involved in gender segregated activities fit for women according to the standards of the Pakistani society, while boys seem to be engaged in more important masculine tasks. The adjectives used for women too were sexist, conservative and showed gender bias.

Hence, it can be concluded from the findings that the representation of gender in these textbooks clearly reinforces the existing patriarchal structure of the country. This highlights the power of textbooks - the invisible power (Foucault, 1980) that normalizes young minds to inculcate these activities and stereotypes learnt through the text and images as a standard which they perform through their acts and behavior towards women in the Pakistani society.

\section{Recommendations}

To reduce the gender biased attitude in textbooks it is suggested that policies related to education need to be revisited on urgent basis. The publishers and the authors of the textbooks may be sensitized about the importance of gender equality and hence they may be guided in the light of the formulated policies. Since, the role of publishers is powerful in establishing and approving gender neutral discourses it is important that they perform validity test before the final approval of books. Finally, the teachers and writers play powerful role in changing gender suitable deeds and attitudes. They can contribute in reducing gender inequality through their writings and teaching.

\section{References}

Alvesson, M. \& Sköldberg, K. (2017). Reflexive Methodology: New Vistas for Qualitative Research. Sage.

Amare, N. (2007). Where is she? Gender Occurrences in Online Grammar Guides. Research in the Teaching of English, pp.163-187.

Anderson, D. L. (2002). A Feminist Tale in Three Moments: Perceptions and Experiences of Adolescent Females in a Feminist Mathematics Classroom (Unpublished Doctoral dissertation). The University of South Florida, Athens, Georgia.

Babbie, E. (1992). The Practice of Social Research. New York: Macmillan. 
Bazler, J. A. \& Simonis, D. A. (1991). Are High School Chemistry Textbooks Gender Fair? Journal of Research in Science and Teaching, vol.28:4, pp.353-362.

Blumberg, R. L. (2009). The Invisible Obstacle to Educational Equality: Gender Bias in Textbooks. Prospects, vol.38:3, pp.345-361.

Clark, R., Allard, J. \& Mahoney, T. (2004). How much of the sky? Women in American High School History Textbooks from the 1960s, 1980s and 1990s. Social Education, vol.68:1, pp.57-63.

Dejene, W. (2017). A Survey of Gender Representation in Social Studies Textbooks of Ethiopian Primary Schools, British Journal of Education, Society \& Behavioural Science, vol.21:1, pp.1-7.

Dominguez, L. M. (2003). Gender Textbook Evaluation. TESL Canada Journal, vol.8:1, pp.32-46.

Dixon, R. M. W. (2005). A Semantic Approach to English Grammar, 2nd edn. Oxford: Oxford University Press.

Fairclough, N. (2001). The Discourse of New Labour: Critical Discourse Analysis. Discourse as Data: A Guide for Analysis, vol.1, pp.229-266.

Foucault, M. (1980). Power/Knowledge: Selected Interviews and other Writing, 1972-1977. Gordon, C. 11(4): 427-40. (ed), Gordon, C et al. (trans). New York: Pantheon.

Fox, M. (1993). Men Who Weep Boys Who Dance: The Gender Agenda between the Lines in Children's Literature. Language Arts, vol.70:2, pp.84-93.

Gisnet, J. (1988). Sexism in English by Television Textbooks. English Teachers' Journal (Israel), 36 - 66.

Government of Pakistan Ministry of Education (2009). National Education Policy 2009. Islamabad, Ministry of Education.

Hellinger, M. (1980). For Men Must Work and Women Must Weep: Sexism in English Language Textbooks in German Schools, Women's Studies Internal Quarterly, vol.3:2, pp.267-275.

Hickey, G. \& Kipping, C. (1996). Issues in Research. A Multi-Stage Approach to the Coding of Data from Open-Ended Questions. Nurse Researcher, vol.4, pp.81-91. 
Hsieh, H. F. \& Shannon, S. E. (2005). Three Approaches to Qualitative Content Analysis. Qualitative Health Research, vol.15:9, pp.1277-1288.

Kobia, J. M. (2009). Femininity and Masculinity in English Primary School Textbooks in Kenya. The International Journal of Language Society and Culture, vol.28, pp.57-71.

Kohl, H. (1995). Should we Burn Baber? Essays on Children's Literature and the Power of Stories. Stanford: CA: University Press.

Kondracki, N. L. \& Wellman, N. S. (2002). Content Analysis: Review of Methods and their Applications in Nutrition Education. Journal of Nutrition Education and Behavior, vol.34, pp.224-230.

Ismail, H., Hamid, A., Yasin, M., Subakir, M., Othman, Z., Keong, Y. C. \& Jaludin, A. (2012). A Study of Gender Positioning and Occupational Roles in Selected Primary School English Language Textbooks. International Journal of Learning, vol.18:12.

Lee, J. F. \& Collins, P. (2009). Australian English-Language Textbooks: The Gender Issues. Gender and Education, vol.21:4, pp.353-370.

Lerner, R, Nagai, A. K. \& Rothman, S. (1992). Filler Feminism in High School History, Academic Questions, vol.5:1, pp.28-40.

Mayring, P. (2000). Qualitative Content Analysis. Forum: Qualitative Social Research, 1(2). Retrieved on March 10, 2005, from: http://www.qualitativeresearch.net/fqs-texte/2-00/02-00mayring-e.htm

McCabe, J., Fairchild, E., Grauerholz, L., Pescosolido, B. A. \& Tope, D. (2011). Gender in Twentieth-Century Children's Books: Patterns of Disparity in Titles and Central Characters. Gender \& Society, vol.25:2, pp.197-226.

Mineshima, M. (2008). Gender Representations in an EFL Textbook. Bulletin of Niigata Institute of Technology, vol.13, pp.121-140.

Neutze, D. L. (2008). Picturing Science: The Who, What and Where of Images in Children's Award Winning Science Trade Books. ProQuest LLC. 789 East Eisenhower Parkway, P.O. 1346, Ann Arbor, M148106.

Ning, N. (1992). Sex Discrimination in Education, Chinese Education, vol.25:1, pp.44-47. 
Oakes, J. \& Saunders, M. (2004). Education's Most Basic Tools: Access to Textbooks and Instructional Materials in California's Public Schools, The Teachers College Record, vol.106:10, pp.1967-1988.

Oyebola, O. (2003). Gender Issues in Textbook Development: A Study of Gender Balance in Illustrations of Selected Textbooks for Upper Primary Level.

Pawelczyk, J., Pakuta, L. \& Sunderland, J. (2014). Issues of Power in Relation to Gender and Sexuality in the EFL Classroom: An Overview. Journal of Gender and Power, vol.1:1, pp.49-66.

Peterson, S. B. \& Lach, M. A. (1990). Gender Stereotypes in Children's Books: Their Prevalence and Influence on Cognitive and Affective Development. Gender and Education, vol.2:2, pp.185-197.

Plumm, K. M. (2008). Technology in the Classroom: Burning the Bridges to the Gaps in Gender-Biased Education?. Computers \& Education, vol.50:3, pp.1052-1068.

Porreca, K. L. (1984). Sexism in Current ESL Textbooks. TESOL Quarterly, vol.18:4, pp.705-724.

Sajjadi, S. (2004). The Representation of Social Actors in the EFL High School Textbooks in Iran, $37^{\text {th }}$ Annual BAAL Meeting Abstracts (143). London: Kings' College.

Skeggs, B. (2002). Formations of Class and Gender. London: Sage.

Skelton, C. (1997). Revisiting Gender Issues in Reading Schemes. Education 313, vol.25:1, pp.37-43.

Skelton, C. (2011, September). Gender and Reading Schemes. In British Educational Research Association Annual Conference, September (pp. 68).

Stockdale, D. A. (2006). Gender Representation in an EFL Textbook. Unpublished Master's Thesis. University of Birmingham, Birmingham, $U K$.

Sulaimani, A. (2017). Gender Representation in EFL Textbooks in Saudi Arabia: A Fair Deal? English Language Teaching, vol.10:6, pp.44-52. 
Tahriri, A. \& Pouran, M. (2014). Gender Representation in "Top-Notch" Series: A Critical Discourse Analysis Perspective. International Journal of Research Studies in Psychology, 3(2), 39-51. https://doi.org/10.5861/ijrsp.2014.633.

Tesch, R. (1990). Qualitative research: Analysis Types and Software Tools. Bristol, PA: Falmer.

Thun, E. (2001). Gender Representation in Educational Materials in the Period of Transition in Hungary. In Webber et al (eds) Education and Civic Culture in Post-Communist Countries (pp. 124-141). Palgrave Macmillan UK.

Turner-Bowker, D. M. (1996). Gender Stereotyped Descriptors in Children's Picture Books: Does "curious Jane" Exist in the Literature?. Sex Roles, vol.35:7-8, pp.461-488.

Ullah, H. \& Haque, H. (2016). The Representation of Boys and Girls Activities in School Textbooks. FWU Journal of Social Sciences, vol.10:1, pp.81-87.

Ullah, H., Ali, J. \& Naz, A. (2014). Gender Representation in Children's Books: A Critical Review of Empirical Studies. World Applied Sciences Journal, vol.29:1, pp.134-141.

Ullah, H. \& Skelton, C. (2014). Social Reproduction of Gender Hierarchies in Sports through Schooling in Khyber Pakhtunkwa, Asia Pacific Journal of Education, vol.36:1, pp.131-144.

Ullah, H. \& Skelton, C. (2013). Gender Representation in Public Sector Schools Textbooks of Pakistan, Educational Studies, vol.4:3, pp.183-194.

Visser, I. (2002). Prototypes of Gender: Conceptions of Feminine and Masculine. Women's Studies International Forum, vol.25:5, pp.529-539.

Rabia Ali is an Assistant Professor in the Department of Sociology, International Islamic University H-10 Islamabad, Pakistan.

Laila Hussain is Lecturer in the Women Degree College Skardu, Gilgit Baltistan. 